(C) 1981. The Genetical Society of Great Britain

\title{
THE GENETICS OF INCOMPATIBILITY IN BRASSICA. I. INHERITANCE OF SELF-COMPATIBILITY IN BRASSICA CAMPESTRIS L. VAR. TORIA
}

\author{
M. I. ZUBERI*, S. ZUBERI* and D. LEWIS \\ Department of Botany and Microbiology, University College London, Gower Street, \\ London WC1E 6BT
}

Received 15.viii.80

\section{SUMMARY}

\begin{abstract}
Using pollen/stigma interactions as the test method and reiterated tests of anomalous results, a single $s$ gene with sporophytic action has been confirmed in Brassica campestris, although some consistent anomalous results could indicate a second complementary gene. Five $s$ alleles have been found in two small samples of a cultivated variety; these alleles show dominance relationships typical of the sporophytic system. A self-compatible allele $s_{c}$ has been found, which is recessive to two alleles in both pollen and style, and dominant in the pollen but recessive in the style to the $s$ allele lowest in the dominance series. Pollen dominance with a lower allele of the series confers a high selective value to $s_{c}$ under the pressure of self-pollination. The action of $s_{c}$ also indicates that the $s$ complex in the sporophytic system consists of at least two genes similar to that in the gametophytic system.
\end{abstract}

\section{INTRODUCTION}

IN several species of the Cruciferae including Brassica campestris L. genetic analyses indicated that self-incompatibility is of the sporophytic homomorphic type and is determined by a series of multiple alleles at the $S$ locus (Bateman, 1955; Thompson, 1957; Sampson, 1957a, 1958). The presence of occasional self-compatible plants among otherwise self-incompatible populations have been reported. In cabbage (Brassica oleracea var. capitata L.) Kakizaki (1930) found a self-compatible plant which segregated in approximately $1: 1$ ratio for self-compatibility and incompatibility. Bateman (1954) identified a self-compatibility allele as a member of the $S$ gene system in Iberis amara and found it to be dominant over one $S$ allele in the pollen. Sampson $(1957 b)$ clearly demonstrated self-compatibility in Brassica oleracea to be due to a gene separate from the $S$ gene by the finding that 4 different $S$ alleles and the self-compatibility segregated in the same family. Self-compatible plants were also reported in self-incompatible populations of cabbage by Thompson and Taylor (1971) and by Thompson (1972), but they attributed this self-compatibility to other major genes outside the $S$-gene system and to competitive interaction between two $S$-alleles. The present paper describes the mode of inheritance of selfcompatibility in Brassica campestris L. var. Toria.

\section{Materials AND Methods}

Seed samples used in the present study are from a collection of Brassica campestris L. var. Toria maintained in the Genetics Laboratory of the

*Permanent Address: Department of Botany, University of Rajshahi, Rajshahi, Bangladesh. 
Botany Department, University of Rajshahi, Bangladesh. The confused taxonomic status of this species has been reviewed and clarified by Wellington and Quartley (1972), and we follow their recommendation in using this name because the material is an oil seed rape and has $2 n=20$ chromosomes, but we stress that the present findings refer to two samples, named $\mathrm{A}$ and $\mathrm{B}$ by us, of the variety Toria. A number of plants were raised from some of these during the winter of 1978-79 in a glasshouse of the University College London. All plants were grown in 4 inch pots in natural daylight supplemented with artificial illumination and at temperatures ranging from $10-18^{\circ} \mathrm{C}$. When the plants were in full bloom they were tested for self-incompatibility. A number of self-incompatible plants were randomly selected and were selfed by bud-pollination, and a few crosses were also made. Further studies carried out on materials involving two original samples are reported here. The first of the samples (Population A) was collected from a local field near the Rajshahi University campus during the winter of 1977-78. Twenty plants were originally sampled and seeds from each plant were kept separate, one of these being used to raise the present material. The second sample (Population B) was collected in 1974 and was maintained in an isolated block in the experimental field as an open pollinated line. Seeds from one such plant were used. The two populations were not only separated in time by three years but were separated by distance of a mile at the place of collection, and are considered to be effectively isolated.

The flowers were usually crossed during the early part of the day; in the case of self-incompatible plants, the flowers were not emasculated but when crossing self-compatible plants, flowers were always emasculated one or two days before opening.

After selfing or crossing, the stigma and part of the style, were collected 24 hours after pollination and were fixed in acetic-alcohol $(1: 3)$. Fixed pistils were squashed in a drop of acid fuchsin-light green stain (Lewis and Crowe, 1958) and examined under a microscope. In the case of compatible pollinations numerous empty, unstained pollen grains with pollen tubes entering into the stigmatic papillae were found. But after incompatible pollination, the pollen grains either did not germinate and so were washed away or produced very short or much coiled tubes outside the stigmatic papilla. In the latter case, a few pollen grains became nearly empty and pollen tubes appeared to enter the papilla thus making observation and determination difficult. In such cases, the fluorescence technique was used. The fixed pistils were softened in $8 \mathrm{~N} \mathrm{NaOH}$ for two hours, washed and stained with aniline blue and the pollen tubes observed with a fluorescence microscope (Kho and Baer, 1968). With this technique, in many of the doubtful cases with half-germinated pollen grains, the pollen tubes were found to be growing in between the papilla rather than into the papilla.

Pollinations where abundant pollen grains were empty and the pollen tubes entering into the stigmatic papilla were scored as compatible $(+)$, pollinations with no empty pollen and no pollen tubes entering in to stigmatic papilla were scored as incompatible $(-)$. Doubtful cases were repeated several times; in relatively few cases, where some pollen tubes (5-10) were repeatedly found to enter into the stigma, the result was scored as intermediate $(+-)$. 
The importance of the pollen/stigma reaction as a reliable assay as opposed to seed set cannot be overstressed. In all cases the individuals of the families were grouped in a matrix on the results before the plants had finished flowering and exceptions to the grouping were repeated several times before acceptance (cf. Lewis, 1979).

Experimental results from intersib pollinations of progeny families are given in checker-board diagrams, where the rows correspond to the female and the columns represent the male parents tested. In genetic interpretations, the dominance of an allele in the pollen is indicated by a dot over the allele, whereas in the stigma it is shown by an underline. Dots or underlines in both alleles indicate co-dominance or individual action.

Forty families from controlled self and cross pollinations have been examined, the fifteen reported here have been completely analysed, the remainder are not reported because they were either too small to be significant or not completely analysed for lack of time, but in no case was a family excluded from complete analysis because of abnormal or nonconforming results.

\section{Results}

\section{(i) Bud-selfed families from Population $A$}

The two bud-selfed families, $6 / 79$ and $7 / 79$, were derived from two plants grown from seeds of a single open-pollinated parent. Details of all the families discussed here are summarized in table 1. The bud-selfed family,

\section{TABLE 1}

Details of the fifteen families included in the study of self-compatibility in Brassica campestris $L$

\begin{tabular}{|c|c|c|c|c|c|c|c|}
\hline \multirow{2}{*}{ Population } & \multirow[b]{2}{*}{ Family } & \multirow{2}{*}{$\begin{array}{l}\text { Seeds } \\
\text { sown }\end{array}$} & \multirow{2}{*}{$\begin{array}{c}\text { Seeds } \\
\text { germinated }\end{array}$} & \multicolumn{2}{|c|}{$\begin{array}{l}\text { Abnormal } \\
\text { seedlings }\end{array}$} & \multicolumn{2}{|c|}{$\begin{array}{l}\text { Abnormal } \\
\text { plants }\end{array}$} \\
\hline & & & & Albino & Purple & Dwarf & Male ste \\
\hline \multirow[t]{4}{*}{ A } & $6 / 79\left(P_{1}\right.$ bud-self $)$ & 40 & 39 & 13 & 3 & 3 & 1 \\
\hline & $7 / 79\left(P_{2}\right.$ bud-self $)$ & 35 & 32 & 3 & 3 & - & - \\
\hline & $8 / 79\left(P_{1} \times P_{2}\right)$ & 40 & 40 & 3 & 1 & - & 一 \\
\hline & $9 / 79\left(P_{2} \times P_{1}\right)$ & 40 & 40 & 2 & - & 一 & 一 \\
\hline \multirow[t]{3}{*}{ B } & $1 / 79\left(P_{1}\right.$ bud-self $)$ & 40 & 30 & 1 & 1 & 3 & 8 \\
\hline & $34 / 79\left(P_{2}\right.$ bud-self $)$ & 12 & 12 & - & 4 & - & 4 \\
\hline & $\begin{array}{l}\text { Six families } \\
\text { derived from } \\
\text { Family } 1 / 79\end{array}$ & 73 & 65 & 一 & - & 5 & 11 \\
\hline $\mathrm{A} \times \mathrm{B}$ & Three families & 79 & 69 & - & - & - & - \\
\hline
\end{tabular}

$7 / 79$, consisted of 26 plants, all of which proved to be self-incompatible and upon inter-sib pollination exhibited a segregation pattern with three groups which can easily be explained on a single $s$ gene with two alleles segregating (fig. 1).

It may be noted that about half of the seedlings in Family 6/79 did not survive beyond the seedling stage. At the flowering stage, three plants (Plants 10, 22 and 23) were found to be morphologically abnormal (small, 


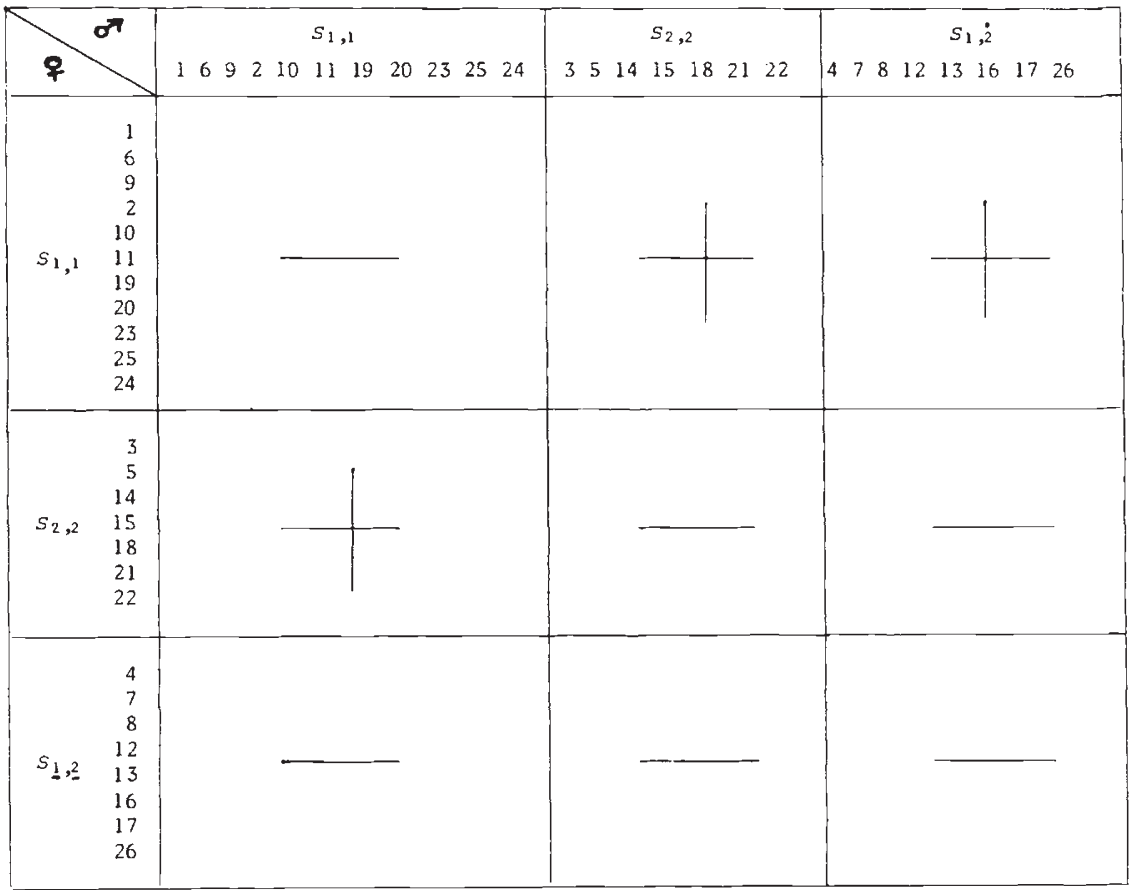

FIG. 1.-Data of the inter-sib pollinations in Family $7 / 79$ derived by bud-selfing a selfincompatible plant of population A. $s$-genotypes $\left(s_{1,1}, s_{2.2}\right.$ and $\left.s_{1,2}\right)$ were assigned to the plants of each mating group assuming a one-gene sporophytic system; $s_{2}$ is dominant over $s_{1}$ in the pollen but co-dominant in the style. + = plants cross-compatible; $-=$ plants incompatible. All possible crosses were made and there were no exceptions.

fleshy leaves; short inflorescences, flowers with often aborted anthers and bad pollen). One plant (Plant 16) was male sterile, another two (Plants 6 and 19) were partially male sterile. All the plants which flowered were found to be self-incompatible and upon inter-sib pollination gave the result summarized in fig. 2. The pattern of inter-sib pollination here is difficult to explain on the basis of a single $s$ gene model alone. Genotypes are tentatively assigned to 4 of the groups but the two plants Nos. 13 and 19 do not conform to a one gene basis and these two plants also divide the $s_{3,4}$ group into two sub-groups.

\section{(ii) Families derived from crosses in Population $A$}

Two families, $8 / 79$ and $9 / 79$, derived from reciprocal crosses between the two plants from which bud-selfed families $6 / 79$ and $7 / 79$ originated, consisted of 36 and 38 plants respectively. All these plants were found to be self-incompatible and the summary of inter-sib pollination results for Family $8 / 79$ are given in fig. 3 . The results for the reciprocal family $9 / 79$ were essentially similar to those of $8 / 79$ as was confirmed by inter-family pollinations, so these are not given. The results can be explained by assuming segregation of two pairs of alleles, thus indicating that both the parents are heterozygous for the $s$ locus. This confirms the results observed 


\begin{tabular}{|c|c|c|c|c|c|c|c|c|}
\hline 우 & 12567811 & 1216 & 1718 & 823 & $\begin{array}{c}5,4 \\
10\end{array}$ & 1319 & $\begin{array}{l}S_{3}, 4 \\
14 \quad 1522\end{array}$ & $\begin{array}{rl} & S_{3,4} \\
34 & 920\end{array}$ \\
\hline $\begin{array}{r}1 \\
2 \\
5 \\
6 \\
7 \\
8 \\
s_{3}, 311 \\
12 \\
16 \\
17 \\
18 \\
23\end{array}$ & 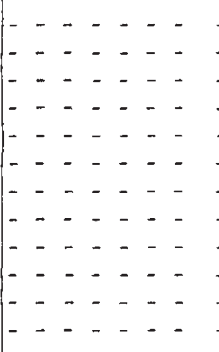 & $\begin{array}{l}- \\
\\
\overline{-} \\
- \\
- \\
- \\
- \\
- \\
- \\
-\end{array}$ & 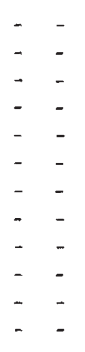 & $\begin{array}{l}- \\
- \\
- \\
- \\
- \\
- \\
- \\
- \\
- \\
- \\
- \\
-\end{array}$ & $\begin{array}{l}+ \\
+ \\
+ \\
+ \\
+ \\
+ \\
+ \\
+ \\
+ \\
+ \\
+ \\
+\end{array}$ & 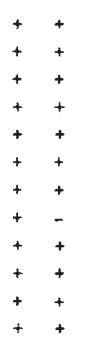 & $\begin{array}{lll}+ & + & + \\
+ & + & + \\
+ & + & + \\
+ & + & + \\
+ & + & + \\
+ & + & + \\
+ & + & + \\
+ & + & + \\
+ & + & + \\
+ & + & + \\
+ & + & + \\
+ & + & +\end{array}$ & $\begin{array}{l}+++++ \\
+++++ \\
+++++ \\
+++++ \\
+++++ \\
+++++ \\
+++++ \\
+++++ \\
+++++ \\
+++++ \\
+++++ \\
+++++ \\
++++\end{array}$ \\
\hline$s_{4,4} 10$ & ++++++ & & ++ & + & - & ++ & ++-+ & ++++ \\
\hline $\begin{array}{l}13 \\
19\end{array}$ & $\ldots-\cdots$ & + & - & - & - & $-\quad-$ & $-\overline{-}-$ & $\begin{array}{l}+++++ \\
++++\end{array}$ \\
\hline $\begin{array}{r}14 \\
S_{3}, 4 \frac{15}{22}\end{array}$ & {$\left[\begin{array}{llll}- & - & - & - \\
- & - & - & - \\
- & - & - & - \\
- & - & -\end{array}\right.$} & $\begin{array}{l}- \\
-\end{array}$ & $\begin{array}{l}- \\
- \\
-\end{array}$ & $\begin{array}{l}- \\
- \\
-\end{array}$ & $\begin{array}{l}- \\
-\end{array}$ & $\begin{array}{l}- \\
- \\
-\end{array}$ & 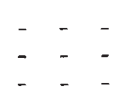 & $\begin{array}{l}\cdots \\
\cdots \\
\cdots \\
\cdots\end{array}$ \\
\hline $\begin{array}{r}3 \\
4 \\
9 \\
S_{3}, 420 \\
21\end{array}$ & 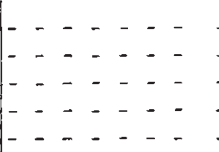 & $\begin{array}{l}- \\
- \\
-\end{array}$ & 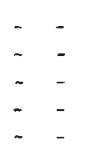 & $\begin{array}{l}- \\
- \\
- \\
-\end{array}$ & $\begin{array}{l}- \\
- \\
- \\
-\end{array}$ & 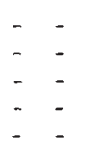 & $\begin{array}{lll}- & - & - \\
- & - & - \\
- & - & - \\
- & - & - \\
- & - & -\end{array}$ & 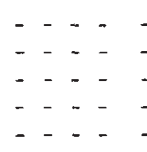 \\
\hline
\end{tabular}

FIG. 2.-Data of the inter-sib pollinations in Family 6/79 derived from a self-incompatible plant (of population A) by bud-selfing. Five mating groups are indicated, as the results cannot be explained following a one-gene sporophytic system alone. Score $+=$ compatible, $-=$ incompatible and $+-=$ intermediate. Plant 16 was male-sterile.

for the bud-selfed Family $7 / 79$ and indicates that though results for Family $6 / 79$ could not be explained, the parent from which it originated by bud-selfing is heterozygous for the $s$ locus.

If the genotype of the parent for $6 / 79$ is assumed to be $s_{3,4}$ and that of the parent for $7 / 79$ be $s_{1,2}$ (as shown in fig. 3 ) the four resulting progeny rlasses expected would be $s_{1,3}, s_{2,3}, s_{1,4}$ and $s_{2,4}$ in an expected $1: 1: 1: 1 \mathrm{ra}$.io, the observed number of plants in the four classes for Families 8/79 and 9/79 taken together were $20,25,13$ and 16 respectively $\left(\chi^{2}=4.4 ; P=0.30-0.10\right.$ with d.f. $=3$ ), there being a considerable deficiency of $s_{4}$ bearing progeny. A similar deficiency of $s_{4}$ alleles is found in the selfed family $6 / 79$, fig. 2 , indicating that the deficiency is due to a linked lethal factor.

(iii) Bud-selfed families of Population $B$

Families $1 / 79$ and $34 / 79$ originated from bud-self pollini tion of two self-incompatible plants grown from a seed-sample of an oper-pollinated 


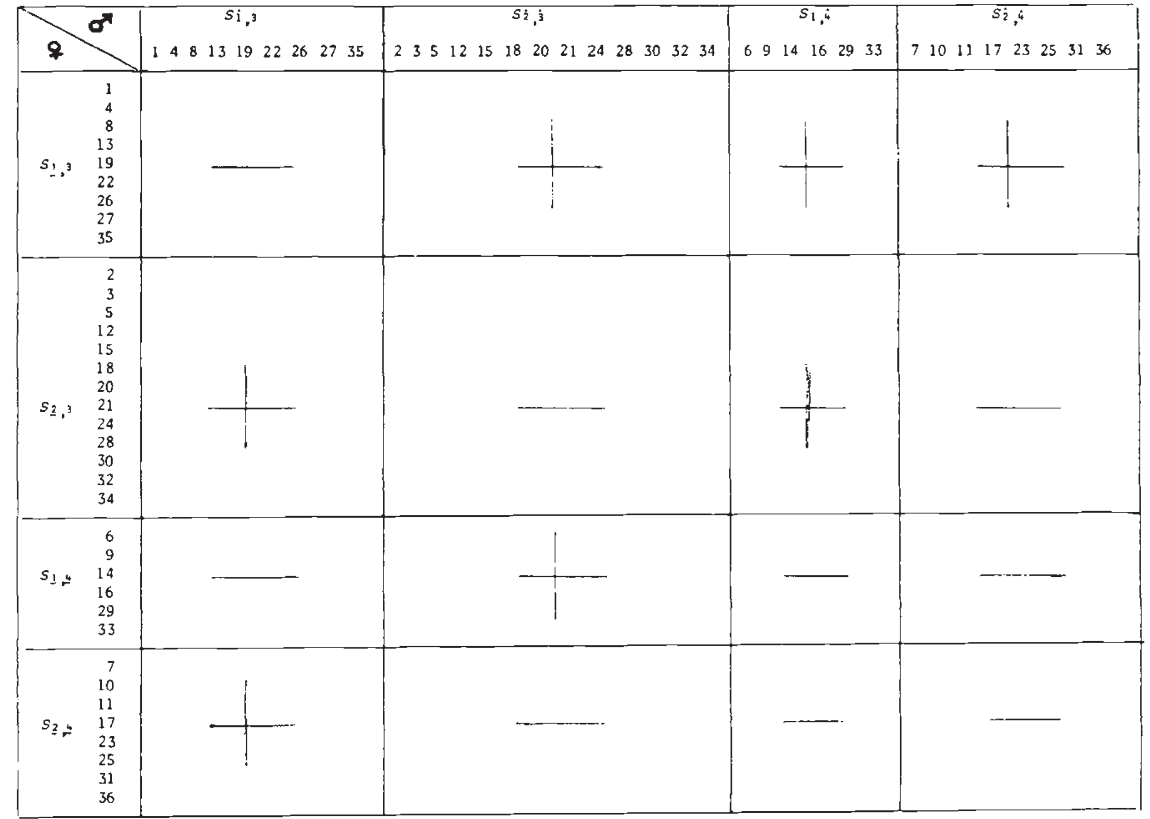

FiG. 3.-Data of the intrafamilial pollinations in Family $8 / 79$ derived from crossing the two parent plants (of population A) from which bud-selfed families $6 / 79$ and $7 / 79$ originated. $s$-genotypes $\left(s_{1,3}, s_{2,3} s_{1,4}\right.$ and $\left.s_{2,4}\right)$ were assigned to the plants of each mating group assuming one-gene sporophytic system and $4 \mathrm{~s}$-alleles in the family. $+=$ plants cross compatible, $-=$ incompatible; a dot over an allele shows dominance in pollen, an underline shows dominance in the stigma. All crosses were made and there were no exceptions.

parent. Inter-sib and self-pollination results for each of the two families gave similar results; details for Family $1 / 79$ only will be given here. There were 25 progeny plants (see table 1 for details) six of which were found to be fully self-compatible whereas the rest were fully self-incompatible. Upon inter-sib pollination, the self-incompatible plants were proved to be incompatible among themselves, but cross-compatible to the self-compatible plants both as male and as female (fig 4). As the parent plant was self-incompatible it was assumed that the gene responsible for self-compatibility in this case is recessive.

To test whether the self-compatibility is allelic to the self-incompatibility, a number of selfs and crosses were nade between the plants of Family $1 / 79$ and also with plants of some other families. Results of six of the crosses and selfs involving plants of Family $1 / 79$ are discussed below.

(a) Families 23/79 and 31/79 were derived from selfing plants 11 and 8 of Family $1 / 79$ respectively. The two plants were self-compatible and their selfed progeny plants, 13 in total, were all found to be selfand inter-sib compatible. Thus the progeny plants as well as the two parents are all proved to be homozygous for the self-compatibility factor.

(b) Families 24/79, 25/79 and 26/79 were derived from crosses $5 \times 11$, $16 \times 14$ and $21 \times 11$ from Family $1 / 79$ respectively where the female 


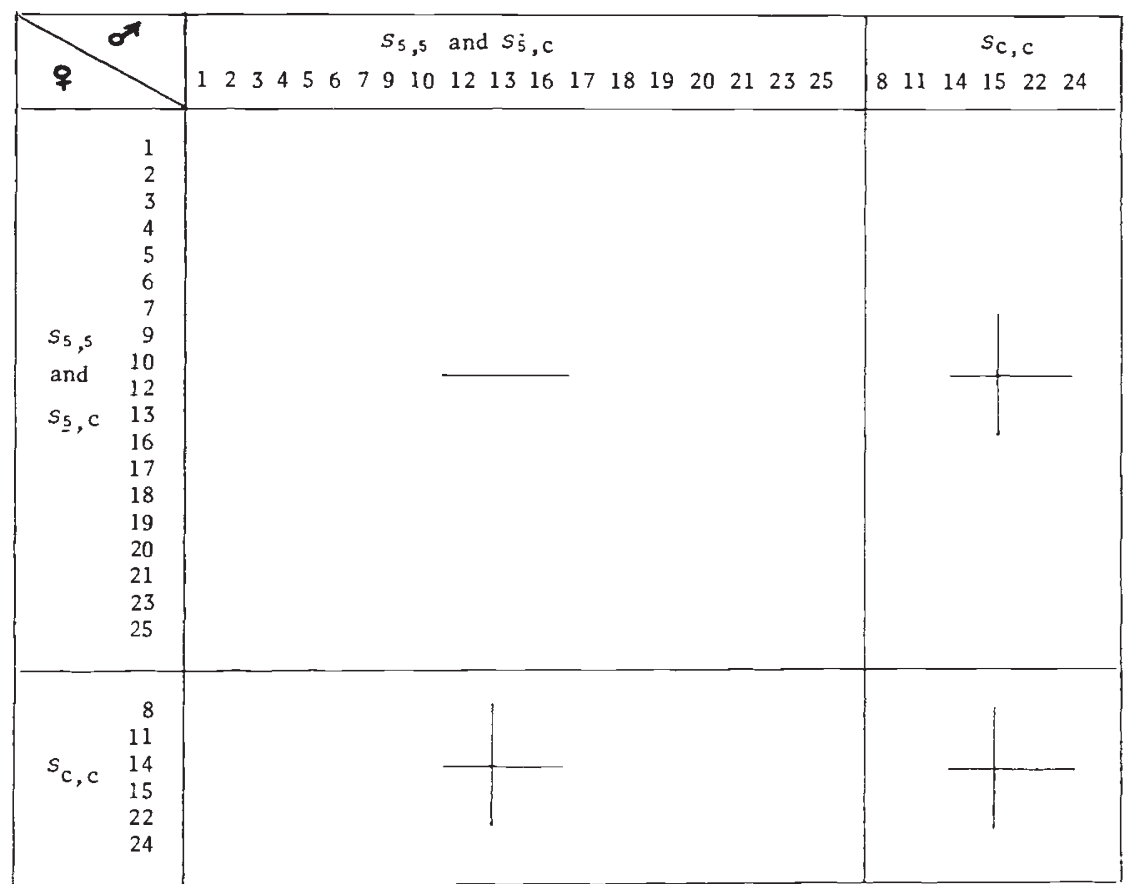

FIG. 4.-Data of the intrafamilial pollinations in Family $1 / 79$ derived by bud-selfing of a self-incompatible plant of population B. $s$-genotypes $\left(s_{5.5}, s_{5, c}\right.$ and $\left.s_{c, c}\right)$ were assigned to the plants of each mating group assuming a one-gene sporophytic system and on the basis of self-compatibility allelic to self-incompatibility; $s_{5}$ is dominant over $s_{c}$. Plants $3,4,5,16$, $18,25,15$ and 22 were completely male-sterile.

parents (plants 5,16 and 21) were all self-incompatible and the male parents (plants 11 and 14) were self-compatible. The progeny plants from each of these three families were found to be of two types just like members of Family 1/79, some self-compatible and some self-incompatible. These results can be explained easily if the incompatible female parents be considered heterozygous for the trait (heterozygous incompatible $X$ homozygous compatible), giving incompatible and compatible progeny in $1: 1$ ratio expected for a back cross. The total number of compatible and incompatible plants observed in these three families were 16 and 13 respectively, giving a good fit to a $1: 1$ ratio.

(c) Family 30/79: self-incompatible plant of Family 1/79 (plant 21) when bud-selfed produced enough seeds to raise Family $30 / 79$ with 10 plants. When these were selfed and inter-sib pollinated, eight incompatible and two compatible progeny were observed. This can be explained by considering the self-incompatible parent (plant 21) as heterozygous for the trait as already stated above, which upon bud-selfing segregated into self-compatible and incompatible in $3: 1$ ratio as in the case of Family 1/79. 


\section{(iv) Crosses between Populations $A$ and $B$}

To obtain further evidence on the allelic nature of self-compatibility, a number of crosses between plants of Families $6 / 79$ and $1 / 79$ were examined.

(a) Families 21/79 and 27/79 were derived from crosses (plant 20 of $6 / 79 \times 13$ of $1 / 79$ and plant 21 of $6 / 79 \times 20$ of $1 / 79$ ) where both the two parents involved are self-incompatible. The self and inter-sib pollinations among the progeny of each of the Families 21/79 and $27 / 79$ produced results which are essentially similar as also proved by inter-family crosses. Only the results for Family $21 / 79$ are given here (fig. 5).

\begin{tabular}{|c|c|c|c|c|}
\hline क & $\begin{array}{c}s_{3,5} \\
345121724\end{array}$ & \begin{tabular}{ccc}
\multicolumn{4}{c}{$\overline{s i, c}$} \\
81619 & 21 & 252918
\end{tabular} & $\begin{array}{ccc} & s_{4}, j \\
91014 & 15232628\end{array}$ & $\begin{array}{c}s_{3, \dot{c}} \\
1267111320222730\end{array}$ \\
\hline $\begin{array}{lr} & 3 \\
& 4 \\
s_{3,5} & 5 \\
& 12 \\
& 17 \\
& 24\end{array}$ & 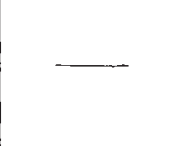 & & $-\ldots$ & - \\
\hline $\begin{array}{rr} & 8 \\
& 10 \\
s_{4,} & 19 \\
& 21 \\
& 25 \\
& 29 \\
& 18\end{array}$ & f & & $\ldots$ & + \\
\hline $\begin{array}{rr} & 9 \\
& 10 \\
& 14 \\
& 15 \\
s_{4,5} & 23 \\
& 26 \\
& 28\end{array}$ & & & -- & $-\cdots$ \\
\hline $\begin{array}{lr} & 1 \\
& 2 \\
& 6 \\
s_{3, \mathrm{c}} \quad & 71 \\
& 13 \\
& 13 \\
& 22 \\
& 27 \\
& 27\end{array}$ & 4 & - - - & + & -1 \\
\hline
\end{tabular}

FIG. 5.-Data of the intrafamilial pollinations in Family 21/79 derived from a cross between two self-incompatible plants of Family $6 / 79$ and $1 / 79$ belonging to populations $A$ and $B$ respectively. $s$-genotypes $\left(s_{3,5}, s_{4, c}, s_{4,5}\right.$ and $\left.s_{3, c}\right)$ were assigned to the plants of each mating group on the basis of a one-gene sporophytic system and self-compatibility allelic to self-incompatibility. $s_{c}$ is dominant over $s_{3}$ in the pollen only.

The results indicate that among the 30 plants examined in the family, ten plants were self-compatible and 20 were self-incompatible. All the ten self-compatible plants were also compatible with all the self-incompatible plants both as male and female. On the other hand, when the 20 self-incompatible plants were crossed among themselves, three different mating groups were observed, is shown in fig. 5 . The above mentioned results can be explained if the 
self-incompatible female parents of Family $6 / 79$ (plants 20 and 21) are considered heterozygous, $s_{3,4}$ (as suggested in section (ii) whereas the male parents, also self-incompatible, from Family 1/79 (plants 13 and 20) were considered heterozygous $s_{5, \mathrm{c}}$ (as indicated in section (iii) above), and that $s_{\mathrm{c}}$ is dominant over $s_{3}$ in the pollen (other dominance relationships are given in fig. 5). Thus the cross involved in Family $21 / 79$ and $27 / 79$ can be genotypically expressed as $s_{3,4} \times s_{5, \mathrm{c}}$ giving $s_{3,5}, s_{3, \mathrm{c}}, s_{4,5}$ and $s_{4, \mathrm{c}}$ progeny with an expected $1: 1: 1: 1: 1$ ratio which fits well to the observed numbers $12,12,9$ and 10 respectively (both families taken together).

(b) Family 22/79 was derived from a cross (plant 20 of $6 / 79 \times 24$ of $1 / 79$ ) where the female parent is self-incompatible but the male is self-compatible. The 22 plants of the family when selfed and intersib pollinated indicated that seven of the progeny plants are selfincompatible and the remaining 15 are self-compatible (fig. 6). As the female parent involved (plant 20 of 6/79) has already been found to be heterozygous $s_{3,4}$, and the male parent (plant 24 of $1 / 79$ ) was of genotype $s_{c, c}$ (see section (iii)), the Family $22 / 79$ should be selfcompatible $\left(s_{3, c}\right)$, and self-incompatible $\left(s_{4, c}\right)$ plants in a $1: 1$ ratio $\left(s_{c}\right.$ being dominant over $s_{3}$ but not $s_{4}$ ); the observed numbers of 15 compatible, 7 incompatible, though not significantly different from

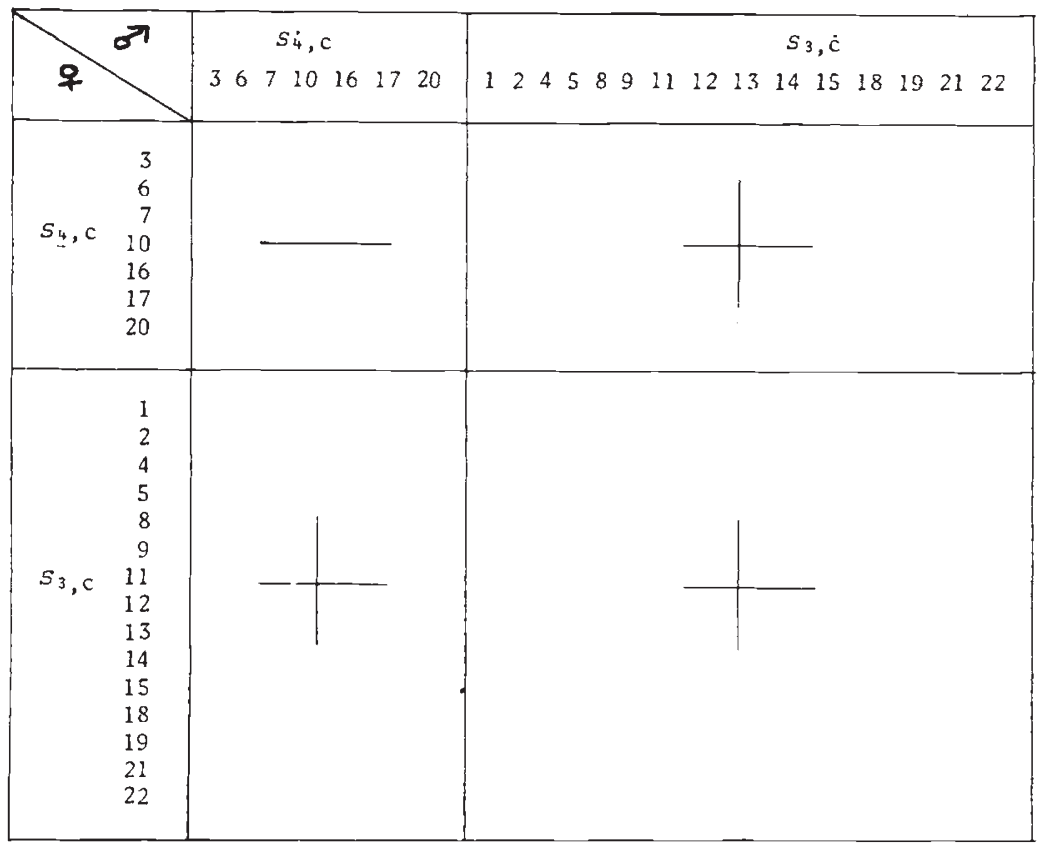

FIG. 6.-Data of the intrafamilial pollinations in Family 22/79 derived from a cross between a self-incompatible plant of Family $6 / 79$ and self-compatible plant of Family 1/79. sgenotypes $\left(s_{4, c}\right.$ and $\left.s_{3, c}\right)$ were assigned to the plants of each mating group assuming a one-gene sporophytic system and self-compatibility allelic to self-incompatibility. $s_{c}$ recessive to $s_{4}$ in pollen but dominant over $s_{3}$. In figs. 4,5 and 6 all crosses in the - groups and 123 in the + groups were made, and there were no exceptions. 
$1: 1$ ratio $\left(\chi^{2}=2 \cdot 9, P=0 \cdot 10-0 \cdot 05\right.$ with 1 d.f. $)$ indicate a deficiency of $s_{4, c}$ plants (see section (i)).

\section{(v) Inter-family pollinations and dominance of alleles}

Due to the small number of crosses analysed so far, no detailed estimate of the number of alleles present in the two populations or dominance relationship between them can be determined at present. However, the analysis of crosses between plants of Families 6/79, 7/79, 8/79 and 1/79 gives some preliminary idea about the dominance relationship between the alleles. The results of these interfamily crosses are summarized in fig. $7 \mathrm{a}$.

A plant derived from Family 6/79 identified as $s_{3,3}$ was used as male onto a plant identified as $s_{3, c}$ obtained from $s_{3,4} \times s_{c, c}$. This cross was fully incompatible, thus showing that $s_{3}$ is dominant to $s_{c}$ in the stigma. The dominance relationship between some of these six alleles in the pollen and the stigma is given in fig. $7 \mathrm{~b}$.
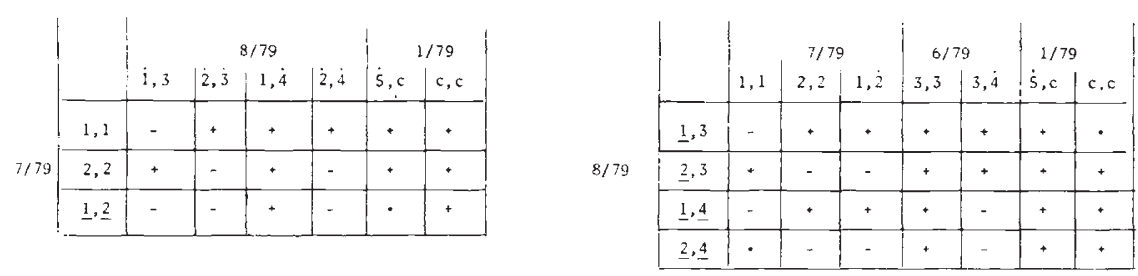

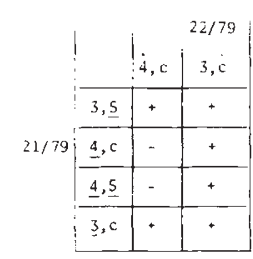

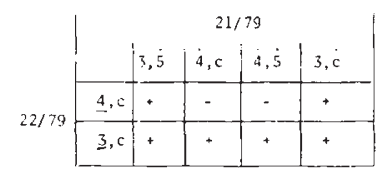

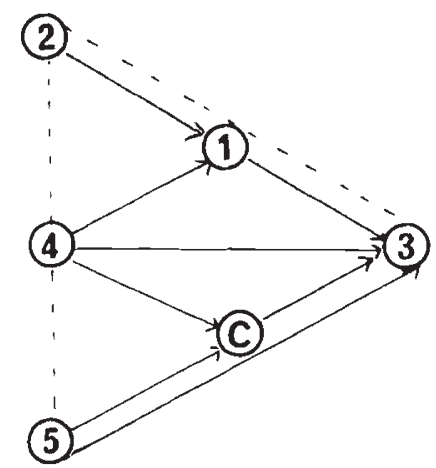

POLLEN

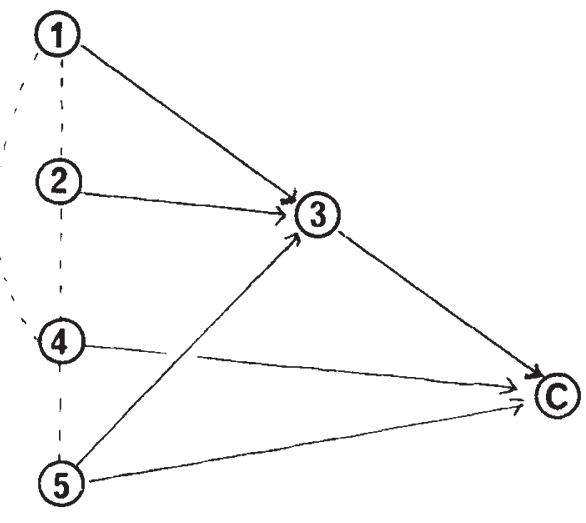

STIGMA

FlG. 7.-Data of interfamily pollinations (fig. 7a) and the dominance relationships between different alleles (fig. 7b). Each allele is shown in a numbered circle; broken lines denote independence of action in heterozygotes; solid lines dominance in the direction of the arrow. 


\section{ONE $S$ GENE OR SEVERAL?}

The establishment of 3 and 4 complementary genes for gametophytic incompatibility in the primitive families, Ranunculaceae and Chenopodiaceae (Lundqvist et al., 1973) and 3 complementary genes in the sporophytic system in Eruca sativa (Verma et al., 1977; Lewis, 1977) make it essential in any new work, be it with an unworked or previously worked species, to keep in mind the possibility of multigenic control. If the hypothesis of Lundqvist is accepted that multigenic systems are primitive and one-gene systems are derived by all but one of the genes becoming silent by homozygosis, then on the one hand the discovery of the silent genes would be difficult and on the other the establishment or refutation of the hypothesis could only be done by searching for these silent genes in a variety of species. It was with this background that the work on Brassica campestris was undertaken.

Of the 15 families analysed completely and described in this paper and 25 other families partly analysed, all but one conform completely to a one-gene system; the one anomalous family can be explained with an additional gene but not by pollen contamination. Full evidence for this is deferred to a later paper. In previous work on Brassica campestris one gene has been invoked to explain five small families (Sareen and Kakar, 1975) and also eight families with one exceptional family with six groups explained on pollen contamination (Richards and Thurling, 1973). Both studies were made by the methods of siliqua formation and seed set, methods which we have found unreliable and, more importantly, with which it is impossible to repeat exceptional results. Mackay (1977) by using the fluorescence staining technique has also demonstrated an $S$ gene with sporophytic control in $B$. campestris but obtained three families which were "inexplicable". There are two main reasons why we are not unequivocally able to answer the question of one $S$ gene or many. First the probability of finding a second gene increases with the degree of diversity and the number of samples tested. The present samples were only two and are probably of similar origin at the time of introduction to cultivation. Secondly, in Raphanus sativus (Lewis, Verma and Zuberi, in preparation) there is a second gene which is active only in certain limited $S$ allelic combinations (cf. Lewis, 1979).

The exceptional family has certain similarities to the Raphanus results and only after analysis of further generations will a clear cut answer emerge in Brassica campestris.

\section{Is THE SELF-COMPATIBILITY GENE ALLELIC WITH THE $S$ GENE?}

Because rigorous information about the genetics of self-compatibility in species with sporophytically determined incompatibility is scanty and inconclusive, we present the results step by step with the alternative explanations:

(1) $s_{c}$ is allelic with the $s$ series, and the $s_{c}$ could be dominant or recessive depending upon the particular accompanying $s$ al'eles.

(2) there is a second gene $I$ independent of the $s$ gene which is necessary for the incompatible matching of $s$ alleles; the homozygote lacking this dominant gene would be self-compatible.

The $I$ gene can be considered to be one of the silent complementary genes, specifying the recognition reaction of the presumed ancestral multigenic 
system, in which case the dominance of $I$ might be conditional on the particular $s$ allele accompanying it. Or it might be an epistatic gene necessary for a step in the synthesis of $s$ molecules but not concerned in the recognition reaction. In this case $i$ should be epistatic to all $s$ alleles. The relevant results and the expectations on the two interpretations are given in figs. $8 \mathrm{a}$ and $8 \mathrm{~b}$.

The genotype of the original parental plant from population $A$ breeds true for self-incompatibility and contains two different $s$ alleles $s_{3}$ and $s_{4}$ as shown by breeding tests. It thereiore cannot carry an $s_{c}$ allele if selfcompatibility is allelic, or it cannot carry the $i$ gene if $s_{c}$ is non-allelic. The parental plant from population $B$, because it segregates for self-compatibility, must either carry an $s_{c}$ allele or be heterozygous $I i$. The one group of self-incompatible plants obtained on selfing this $\vec{B}$ parental plant proves that only one $s$ allele, $s_{c}$, is present. With the allelic situation, $s_{c}$ is present in one dose and in the nonallelic situation in 2 doses. With the genotypes of the parental plants fixed, the genotypes of the subsequent generations follow from normal diploid segregation. The genes $s$ and $I$ are shown to be linked; the end result is the same if they are independent, so the results exclude a second gene be it independent or adjacent to $s$. It is interesting that the discrimination is obtained only from the intercross between the two populations, and further results from within the single population $B$ could not resolve the question (cf. Bateman, 1954).

The discrimination between the allelic and non-allelic explanation appears to be so decisive that possible variations on the basic hypotheses due to dominance and gene interactions are explored to eliminate any false

POPULATION A POPULATION B

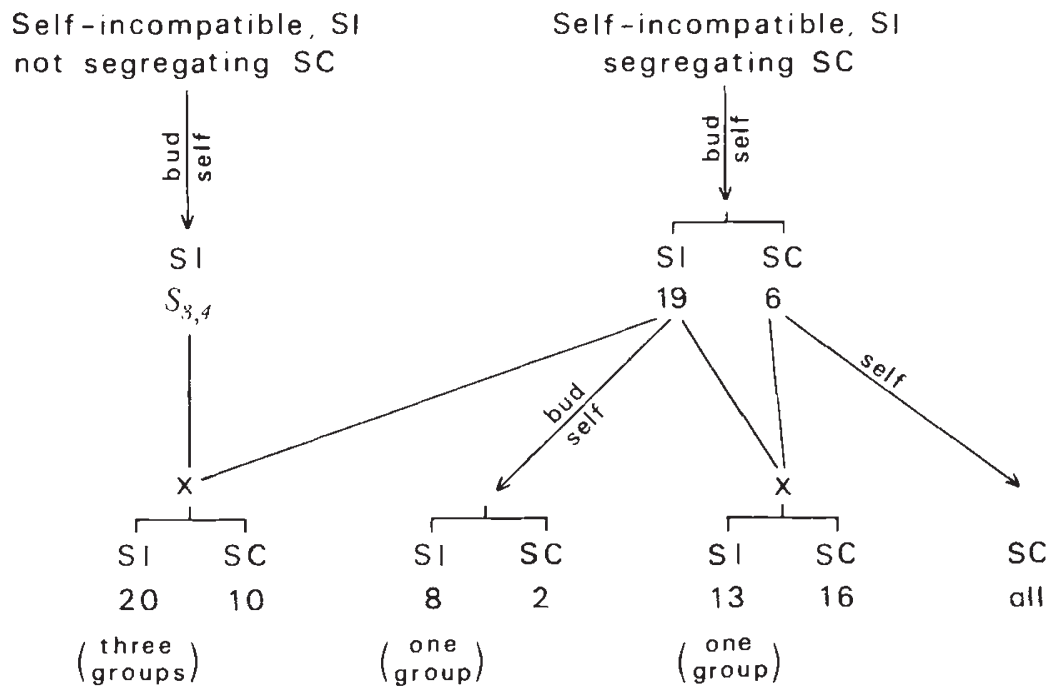

FIG. 8a.-A summary of results relevant to the inheritance of self-compatibility. The numbers refer to numbers of plants of a particular class, $S I$ or $S c$ in a family, and the number of groups refers to the different groups obtained by testing the $S I$ plants inter se. 


\section{POPULATION B INTERPRETATION}

SI

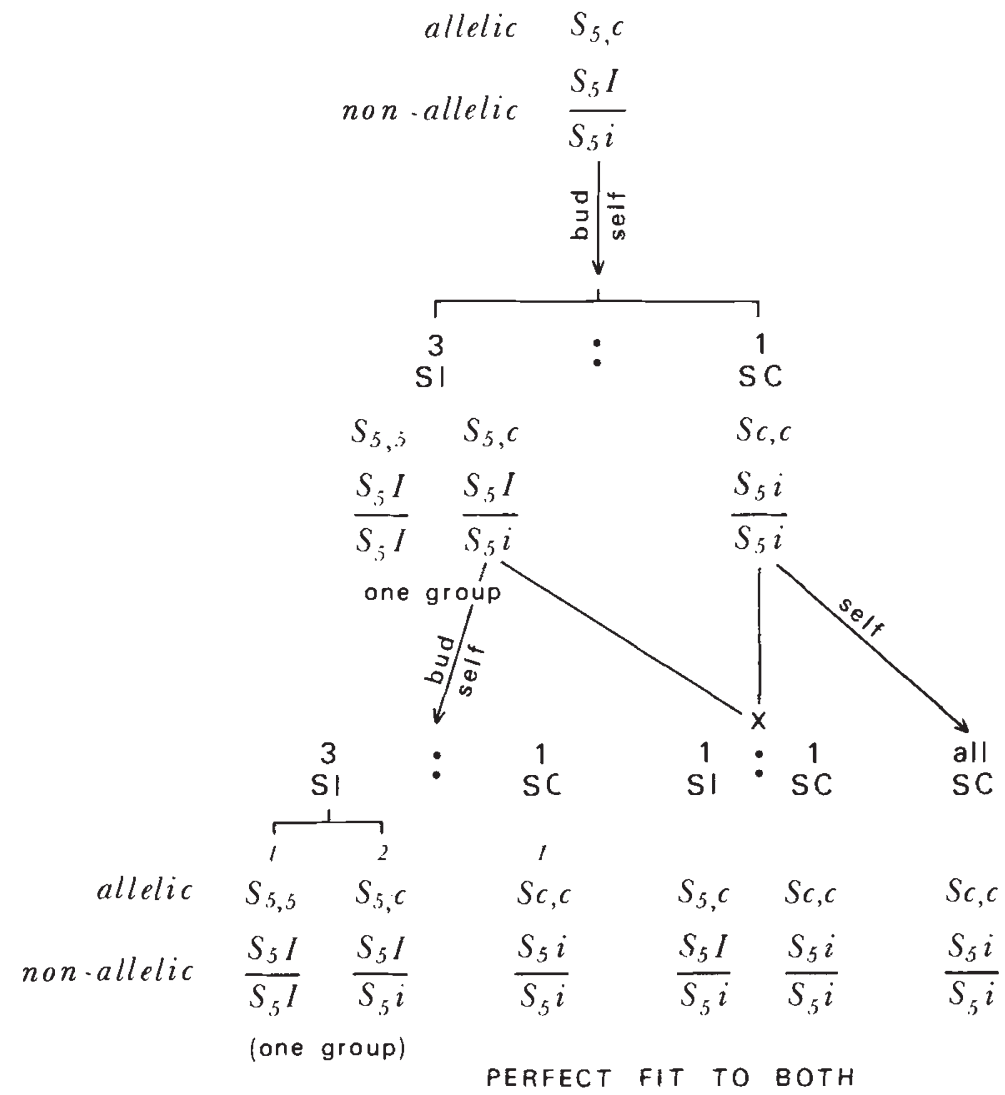

INTERPRETATION BETWEEN POPULATIONS A AND B ALLELIC NON-ALLELIC

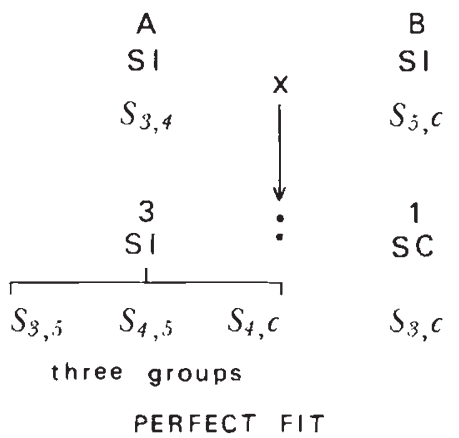

A B

SI

SI

$\frac{S_{33} I}{S_{4} I}$

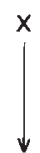

$\frac{S_{5} I}{S_{5} i}$

all $\mathrm{SI}$

$\begin{array}{llll}\frac{S_{3} I}{S_{5} I} & \frac{S_{3} I}{S_{5} i} \quad \frac{S_{4} I}{S_{5} I} & \frac{S_{4} I}{S_{5} i}\end{array}$

FAILS on absence of $\mathrm{SC}$ and only two groups

FIG. 8b.-Interpretation on an allelic basis with $s_{c}$ being recessive to $s_{5}$ and $s_{4}$ but dominant to $s_{3}$; and on a non-allelic basis of a gene $I . i$ in which only $i i$ is self-compatible. Linkage is shown in the model to show that both an independent and tightly linked non-allelic gene are excluded. 
conclusions. On the allelic hypothesis it is possible for $s_{c}$ to be dominant with one of the three alleles, as given in fig. $8 \mathrm{a}$, or with two alleles or with none. These three dominance situations generate the following types of families:

$\begin{array}{ccc}\text { Segregating } \\ \text { Family } \\ \text { Dominance of } S_{c} & \text { SI:SC } & \begin{array}{c}\text { Number of } \\ \text { SI groups }\end{array} \\ 0 \rightarrow & 4: 0 & 2,3 \text { or } 4 \\ 1 \rightarrow & 3: 1 & 2^{*} \text { or } 3 \\ 2 \rightarrow & 2: 2 & 2\end{array}$

All groups of SI plants are expected to contain the same number of plants except $2^{*}$ in which one group will contain two genotypes and have twice as many plants as the other.

The theoretical results obtained with a non-allelic gene would appear to be invariate although it is possible but unlikely, that the dominance of $I$ over $i$ might be conditional on the particular $s$ allele pair accompanying it, e.g., the gene $I$ might not be operating in the genotype $s_{3} I / s_{5 i}$, and this would be self-compatible. This would contribute to the generation of a family which consists of $3 S I$ : $1 S C$ with the $3 S I$ containing two groups of unequal size. The only possible overlap between these variations of the two hypotheses is with this conditional reversal of dominance of $I$ with the allelic dominance $I$ which gives $3 S I$ ( $2 *$ groups): $1 S C$. The result obtained is unique to the allelic variations and cannot be confused.

\section{IS THE $S$ GENE A COMPLEX IN THE SPOROPHYTIC SYSTEM?}

The action of the $s_{c}$ allele in Brassica campestris raises the question of the structure of the $s$ gene in the sporophytic homomorphic system. It has been generally accepted that the two other major incompatibility systems have a number of tightly linked genes which constitute the $s$ complex, usually referred to as the $s$ gene (Lewis, 1976; Pandey, 1967; de Nettancourt, 1977). Some of the separate genes separate the control of recognition of the pollen and the style. The evidence for this complex has come from mutations in the gametophytic system and from rare recombinations in the heterostyled system. There is, however, no hard evidence for such an $s$ complex in sporophytic incompatibility, for no such mutations or recombinations have been found, probably for the reason that the system does not have an efficient natural means for their selection. The most suggestive evidence for a complex of genes is the different dominance relationships of alleles in pollen and stigmas of all species studied. The action of $s_{c}$ in Brassica campestris, by analogy with the $s_{c}$ alleles obtained by mutation in the gametophytic systems, reinforces this suggestion. The $s_{c}$ allele is recessive in the stigma to three alleles, including $s_{3}$, and is recessive to two of these but dominant to $s_{3}$ in the pollen.

The origin of $s_{c}$ is unknown except that it was found in population B; it probably arose as a functional loss mutation of the pollen-determining gene. Without the ancestral allele we cannot test conclusively for the structure of 
the $s$ gene. This can be done only with an $s_{c} s_{c}$ stigma showing incompatibility to pollen with the ancestral $s$ phenotype.

\section{HOW IS SELF-COMPATIBILITY IN SPOROPHYTIC SYSTEMS SELECTED IN NATURE?}

Mutations of the $s$ gene to self-compatibility in the gametophytic system can be selected with high efficiency by self-pollination, and this gives a means of survival to a species when self-pollination is enforced by either the isolation of an individual plant or if it is deprived of an insect pollinator. The efficiency of the selection depends upon the gametophytic action of the $s$ gene in the haploid pollen so that recessive $s_{c}$ mutants are not masked and are immediately expressed in the pollen grain. In the sporophytic system where the $s$ gene operates at the latest in the diploid pollen mother-cell or at the earliest in the tetraploid tapetum tissue, $s_{c}$ mutants being recessive would not be selected by the self stigmatic tissue and to be expressed would have to be homozygous in a plant in a future generation. The present $s_{c}$ allele offers a compromise; by being dominant over one $s$ allele $\left(s_{3}\right)$, which itself is low in the dominance series, it would be selected by the self stigma if the mutation occurred early in the development of an anther of the plant homozygous for $s_{3} s_{3}$. Because $s_{3}$ is low in the dominance series homozygotes would be present in the population. The effective frequency of such mutations would depend upon the precise place of action of the $s$ gene. If in the tapetum the mutants, to be selected, would have to occur early in the development of the anther and in this case the frequency would be low but would produce whole anthers of mutant pollen grains. If on the other hand the action is in the pollen-mother-cell the mutations would be many orders of magnitude more frequent, but each would produce only about four mutant pollen grains. In either case a dominant $s_{c}$ mutation in a recessive homozygote provides a moderately efficient method of generation and selection of self-compatibility in the sporophytic system.

Acknowledgements. - The Royal Commission for the Exhibition of 1851 supported one of us (M.I.Z.) for this work. The Leverhume Trust supported D.L. in the form of an Emeritus Fellowship. Both are gratefully acknowledged.

\section{REFERENCES}

BATEMAN, A. J. 1954. Self-incompatibility in angiosperms. II. Iberis amara. Heredity, 8, 305-332.

BATEMAN, A.J. 1955. Self-incompatibility systems in angiosperms. III. Cruciferae. Heredity, 9, 53-68.

KAKIZAKI, Y. 1930. Studies on the genetics and physiology of self and cross-incompatibility in the common cabbage (Brassica oleracea L. var. capitata L.). Jap. J. Bot, 5, 133-208.

KHO, Y. O, AND BAER, J. 1968. Observing pollen tubes by means of fluorescence. Euphytica, $17,298-302$.

LEWIS. D. 1976. Incompatibility in flowering plants. In Receptors and Recognition, eds. Cuatrecases and Greaves, 2. Series A. Chapman \& Hall, London.

LEWIS, D. 1977. Sporophytic incompatibility with 2 and 3 genes. Proc. R. Soc. Lond. B., 196, $161-170$.

LEWIS, D. 1979. Genetic versatility of incompatibility in plants. New Zealand J. Bot., 17, 637-644. 
LEWIS, D., AND CROWE, L. K. 1958. Unilateral interspecific incompatibility in flowering plants. Heredity, 12, 233-256.

LUNDQVist, A. U., ØSTERBYE, K. LARSEN, AND LiNDE LAUREN, I. B. 1973. Complex self-incompatibility systems in Ranunculus acris L. and Beta vulgaris L. Hereditas, 74, 161-168.

MACKAY, G. R. 1977. A diallel cross method for the recognition of $S$ allele homozygotes in turnip Brassica campestris L. ssp rapifera. Heredity, 38(2), 207-208

NETTANCOURT, D. de. 1977. Incompatibility in Angiosperms. Springer-Verlag, Berlin.

PANDEY, K. K. 1967. Elements of the s-gene complex II. Heredity, 22, 255-84.

RICHARDS, R. A., AND THURLING, N. 1973. The genetics of self-incompatibility in Brassica campestris L. ssp. Oleifera Metzg. I. Characteristics of $S$-Locus. Control of Selfincompatibility. Genetica, 44, 428-438.

SAMPSON, D. R. $1957 a$. The genetics of self-incompatibility in the radish. J. Heredity, 48 , 26-29.

SAMPSON, D. R. $1957 \mathrm{~b}$. The genetics of self- and cross-incompatibility in Brassica oleracea. Genetics, 42, 253-263.

SAMPSON, D. R. 1958. The genetics of self-incompatibility in Lesquerella densipila and in $F_{1}$ hybrid of $L$. densipila $\times$ L. lescurii. Canad. J. Bot., 36, 39-56.

SAREEN, P. K., AND KAKAR, S. N. 1975. Genetics of incompatibility in brown sarson (Brassica campestris L.). Z. Pflanzenzüchtg, 74, 291-297.

THOMPSON, K. F. 1957. Self-incompatibility in marrow-stem kale, Brassica oleracea var. acephala. I. Demonstration of a sporophytic system. J. Genet., 55, 45-60.

THOMPSON, K. F. 1972. Competitive interaction between two-alleles in a sporophytically controlled incompatibility system. Heredity, 28, 1-8.

THOMPSON, K. F., AND TAYLOR, J. P. 1971. Self-compatibility in kale. Heredity, 27, 459-471.

VERMA, S. C., MALIK, R., AND DHIR, I. 1977. Genetics of the incompatibility system in the crucifer Eruca sativa L. Proc. R. Soc. Lond. B., 196, 131-159.

WELLINGTON, P. S., AND QUARTLEY, C. E. 1972. A practical system for classifying, naming and identifying some cultivated Brassicas. J. natn. Inst. agric. Bot. 12, 413-432. 